\title{
Micro-structural evolution of rubber/clay nanocomposites with vulcanization process
}

\author{
Y-L. $L u^{1,2,3}, F-Y . Y e^{1}, L-X . M a o^{1}, Y . L i^{1}, L-Q . Z^{2} \operatorname{lang}^{1,2,3^{*}}$ \\ ${ }^{1}$ Key Laboratory of Beijing City on Preparation and Processing of Novel Polymer Materials, College of Polymer Science \\ and Engineering, Beijing University of Chemical Technology, Beijing 100029, PR China \\ ${ }^{2}$ Key Laboratory of Carbon Fiber and Functional Polymers, Ministry of Education, College of Polymer Science and \\ Engineering, Beijing University of Chemical Technology, Beijing 100029, PR China \\ ${ }^{3}$ Key Laboratory for Nanomaterials, Ministry of Education, College of Polymer Science and Engineering, Beijing \\ University of Chemical Technology, Beijing 100029, PR China
}

Received 31 December 2010; accepted in revised form 10 March 2011

\begin{abstract}
Brominated isobutyl-isoprene rubber/clay nanocomposite (BIIRCN) and ethylene-propylene-diene-monomer rubber/clay nanocomposite (EPDMCN) were prepared by melt blending. The micro-structural evolution of these two kinds of rubber/clay nanocomposites (RCNs) with vulcanization process was investigated using wide-angle X-ray diffraction (WAXD) and transmission electron microscope (TEM). The WAXD results revealed that the intercalated structure of organically modified clay (OMC) changed throughout the whole curing process. The intercalated structure kept on changing beyond the vulcanization stage of $T_{90}$. The interlayer space of intercalated silicate in uncured BIIRCN is larger than that in uncured EPDMCN. However, the intercalated structure for EPDMCN changed by a larger extent than that for BIIRCN during the vulcanization process, and the interlayer space of the intercalated structure is larger in the cured EPDMCN than that in the cured BIIRCN. It was found that the intercalant (i.e., octadecylamine, ODA) for OMC could shorten the scorch time of the curing reaction, and increase the curing rate, which was attributed to the further intercalation during vulcanization. TEM results indicated that the spatial distribution of OMC is much better in BIIR (a polar rubber matrix) than that in EPDM (a non-polar rubber matrix). The changes in spatial dispersion structure during vulcanization for EPDMCN and BIIRCN show different trends. In conclusion, the polarity of the rubber is the determining factor influencing the evolution of both the intercalated structure and the spatial dispersion of clay during vulcanization.
\end{abstract}

Keywords: nanocomposites, organoclay, vulcanization, intercalated structure, spatial distribution

\section{Introduction}

In recent years, rubber/clay nanocomposites (RCNs) have become a research focus because of their high strength, gas barrier, and flame resistance. Up to date, four processing methods, including in-situ polymerization intercalation [1], solution intercalation [2], melt intercalation [3-5], and latex compounding [6-8], have been developed for preparation of RCNs. Among them, melt compounding is the most practical method, because existing rubber processing equipment can be used and no organic solvent is needed.

The dispersion state of organically modified clay (OMC) in the rubber matrix determines the final properties of the composite. There are many factors that impact the microstructure of RCNs prepared by melt compounding. Previous studies have shown that the type of intercalant [9-12], the compounding conditions (shear stress and temperature) $[13,14]$, as well as the polarity of the rubber [15] have sig-

\footnotetext{
${ }^{*}$ Corresponding author, e-mail: zhanglq@mail.buct.edu.cn

(c) BME-PT
} 
nificant impact on the dispersion state of OMC in the rubber matrix. In addition, significant changes in the microstructure of RCNs also occur during the curing process at high temperature and high pressure [16-18]. However, there is still some fuzziness in the mechanism and reasons for this change in clay dispersion during the curing process until now. In particular, the microstructural evolution of RCNs with the vulcanization course has not been reported. In the present work, brominated isobutyl-isoprene rubber/clay nanocomposites (BIIRCN) and ethylene propylene diene monomer rubber/clay nanocomposites (EPDMCN) were prepared by melt intercalation, and the evolution of both intercalation structure and spatial dispersion of clay layers in these two kinds of RCNs during vulcanization process was studied. We observed some unexpected phenomenon that might have provided us with a new idea to prepare well-dispersed rubber/clay nanocomposites. At the same time, the role of intercalants and the polarity of matrix rubber on microstructure evolution were discussed.

\section{Experimental}

\subsection{Materials and basic formulation}

Brominated isobutyl-isoprene rubber (BIIR, 2030) with the $\mathrm{Br}$ content of $2.0 \pm 0.3 \%$, the unsaturation degree of $\sim 1.95 \%$ and the Mooney viscosity $\left(M L_{1+8}^{125^{\circ} \mathrm{C}}\right)$ of $32 \pm 4$ was produced by Bayer, Germany. Ethylene propylene diene monomer rubber (EPDM, 4050) with ethylene content of $52 \%$, ethylidene norbornene (ENB) content of $6.7 \mathrm{~g} / 100 \mathrm{~g}$, and the $M L_{1+4}^{100^{\circ} \mathrm{C}}$ of $\sim 45$ was provided by Jilin Petrochemical Company, China. The organically modified clay (OMC, I.30P) with an initial basal spacing of $2.36 \mathrm{~nm}$ was purchased from Nanocor, USA. Pristine sodium montmorillonite (Na-MMT) was supplied by Liufangzi Mining Co. Ltd, Siping City, Jilin Providence, China. Other materials and agents were commercial products. In order to obtain organic intercalant (i.e., octadecylamine, ODA) from the OMC (I.30P), some amounts of OMC were subjected to $48 \mathrm{~h}$ Soxhlet extraction at $95^{\circ} \mathrm{C}$ with anhydrous ethanol. The residual extraction solution of ethanol was evaporated at $100^{\circ} \mathrm{C}$. The obtained substance was pestled and dried to obtain ODA. The formulations for rubber compounds used in this work are listed in Table 1.

\subsection{Preparation of samples}

The rubber and OMC (or, Na-MMT and ODA) were first compounded uniformly on a two-roll mill (Zhanjiang Rubber and Plastic Machinery Factory, China) according to the formulation given in Table 1, and the other agents were gradually mixed into the compound.

Besides BIIRCN and EPDMCN, the neat BIIR and EPDM containing MMT or ODA compounds were also prepared according to the formulation given in Table 1, in order to analyse the influence of OMC on vulcanization course of matrix. The rubber compounds were prepared by a 6 inch two-roll mill blending in the following addition order of the ingredients: the $\mathrm{EPDM} \rightarrow \mathrm{ZnO} \rightarrow \mathrm{SA} \rightarrow$ additive. In this study, we used OMC, MMT, and ODA as fillers for EPDM in the amounts of 10, 7, and $3 \mathrm{phr}$, respectively.

The vulcanization curves of the rubber compounds at $150^{\circ} \mathrm{C}$ were examined by using a disc oscillating rheometer (P3555B2, Beijing Huanfeng Chemical Technology and Experimental Machine Plant, China). Figure 1 shows the curing curves of BIIRCN and EPDMCN at $150^{\circ} \mathrm{C}$. The curing times for different curing stages, $T_{\mathrm{i}}$ (i.e., $T_{10}, T_{20}, \ldots T_{90}, T_{100}$ ),

Table 1. Formulations for rubber compounds

\begin{tabular}{|l|c|c|c|c|c|}
\hline \multirow{2}{*}{ Materials } & \multicolumn{5}{c|}{ Loading [phra } \\
\cline { 2 - 6 } & BIIRCN & EPDMCN & EPDM & E-ODA & E-MMT \\
\hline BIIR & 100 & - & - & - & - \\
\hline EPDM & - & 100 & 100 & 100 & 100 \\
\hline Organoclay (OMC) & 10 & 10 & - & - & - \\
\hline ODA & - & - & - & 3 & - \\
\hline Na-MMT & - & - & - & - & 7 \\
\hline Zinc oxide (ZnO) & 5.0 & 5.0 & 5.0 & 5.0 & 5.0 \\
\hline Stearic acid (SA) & 2.0 & 2.0 & 2.0 & 2.0 & 2.0 \\
\hline Tetramethyl thiuram disulfide (accelerator TMTD) & 1.0 & 1.0 & 1.0 & 1.0 & 1.0 \\
\hline 2-Mercapto benzothiazole (accelerator M) & 0.5 & 0.5 & 0.5 & 0.5 & 0.5 \\
\hline Sulfur (S) & 1.8 & 1.8 & 1.8 & 1.8 & 1.8 \\
\hline
\end{tabular}

${ }^{\mathrm{a}} \mathrm{phr}$ is the abbreviation of parts per hundreds of rubber 

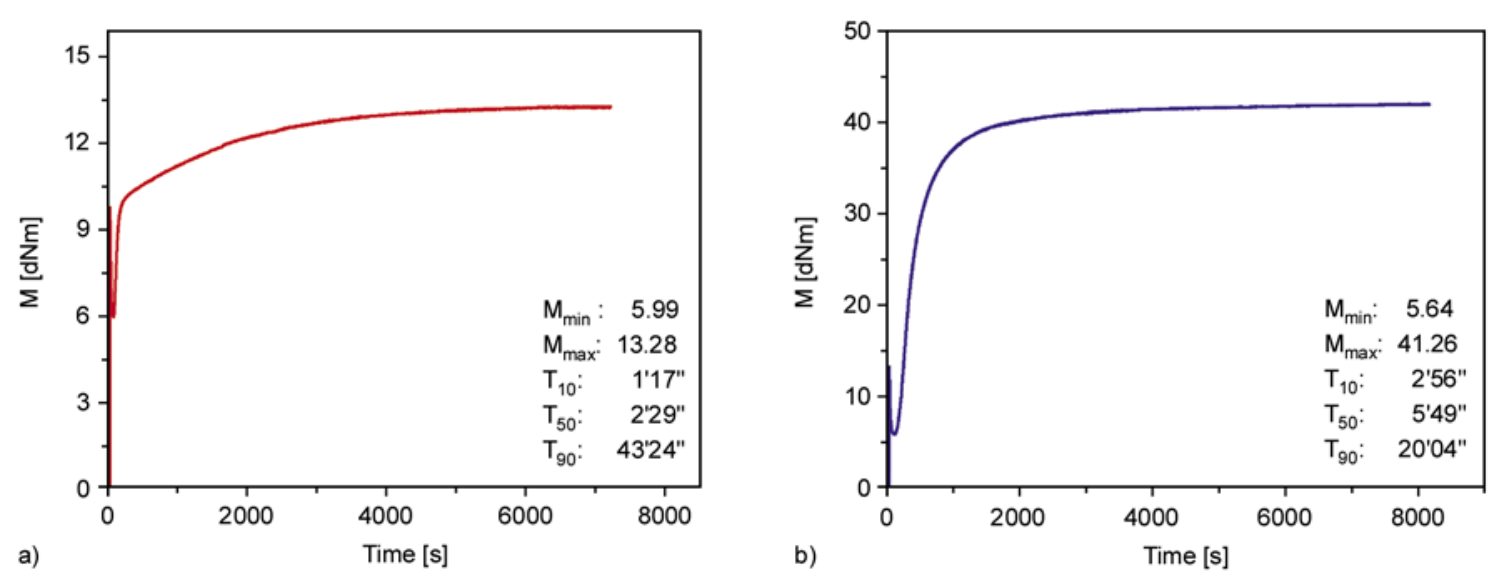

Figure 1. Curing curves at $150^{\circ} \mathrm{C}$ of (a) BIIRCN and (b) EPDMCN

Table 2. Curing times for different cure stages of BIIRCN and $\mathrm{EPDMCN}$ at $150^{\circ} \mathrm{C}$

\begin{tabular}{|c|c|c|}
\hline \multirow{2}{*}{ Cure stage } & \multicolumn{2}{|c|}{ Cure time [s] } \\
\cline { 2 - 3 } & BIIRCN & EPDMCN \\
\hline$T_{0}$ & 0 & 0 \\
\hline$T_{10}$ & 77 & 176 \\
\hline$T_{20}$ & 88 & 216 \\
\hline$T_{30}$ & 100 & 252 \\
\hline$T_{40}$ & 117 & 295 \\
\hline$T_{50}$ & 149 & 349 \\
\hline$T_{60}$ & 348 & 423 \\
\hline$T_{70}$ & 875 & 536 \\
\hline$T_{80}$ & 1549 & 733 \\
\hline$T_{90}$ & 2604 & 1204 \\
\hline$T_{100}$ & 6889 & 8070 \\
\hline
\end{tabular}

were calculated as following procedure: (1) the difference between the maximum torque $\left(M_{\max }\right)$ and the minimum torque $\left(M_{\mathrm{min}}\right)$ of the curing curves, $\Delta M=M_{\max }-M_{\min }$, was calculated; (2) the torques at various curing stages $\left(M_{\mathrm{i}}\right)$ were calculated from the equation, $M_{\mathrm{i}}=M_{\min }+\Delta M \cdot i \%$, e.g., $M_{10}=$ $M_{\text {min }}+\Delta M \cdot 10 \%, M_{20}=M_{\min }+\Delta M \cdot 20 \%, \ldots M_{90}=$ $M_{\min }+\Delta M \cdot 90 \%$; and (3) the cure time $\left(T_{\mathrm{i}}\right)$ corresponding to $M_{\mathrm{i}}$ was obtained from the vulcanization curve. The resultant curing time for BIIRCN and EPDMCN at different vulcanization stages are summarized in Table 2.

The RCNs were vulcanized by a plate vulcanizing press ( 25 tons, Shanghai Rubber Machinery Factory, China) to the time for different curing stages $\left(T_{\mathrm{i}}\right)$ at $150^{\circ} \mathrm{C}$ and $15 \mathrm{MPa}$. The vulcanized specimens have the dimension of $132 \mathrm{~mm} \times 112 \mathrm{~mm} \times$ $1 \mathrm{~mm}$. The samples were promptly removed from the mold when the curing time reached predetermined $T_{\mathrm{i}}$, and then rapidly quenched in cold water to stop the curing reaction. We denoted the BIIRCN and EPDMCN nanocomposites whose curing stage is at $T_{\mathrm{i}}$ as BIIR- $T_{\mathrm{i}}$ and EPDM- $T_{\mathrm{i}}$, respectively. The uncured samples, BIIR- $T_{0}$ and EPDM- $T_{0}$, were prepared by filling the mold with BIIRCN and EPDMCN compounds, respectively, and then pressed at $60^{\circ} \mathrm{C}$ and $15 \mathrm{MPa}$ for $30 \mathrm{~min}$ and finally for another $30 \mathrm{~min}$ at room temperature.

\subsection{Characterization}

WAXD measurements were carried out on a RINT diffractometer (D/max-IIIC, Rigaku Corporation, Japan) with a $\mathrm{Cu}-\mathrm{K}_{\alpha}$ radiation $(40 \mathrm{kV}, 200 \mathrm{~mA})$ in the $2 \theta$ range of 0.5 to $10^{\circ}$ at a scan rate of $1 \% \mathrm{~min}$. The spatial dispersion state of OMC in the rubber matrix was observed on a transmission electron microscope (TEM) (H-800, Hitachi, Japan) with an acceleration voltage of $200 \mathrm{kV}$. Ultra-thin sections of RCNs were cut by using a microtome at $-100^{\circ} \mathrm{C}$ for the TEM experiments.

\section{Results and discussion}

\subsection{The evolution of intercalated structure of rubber/clay nanocomposites during curing process}

Wide-angle X-ray diffraction (WAXD) is a very useful tool for the study of polymer/clay nanocomposites. It can directly determine the intercalation of polymer molecules in the silicate gallery. Figure 2 displays the WAXD patterns of BIIRCN and EPDMCN at different curing stages. It can be seen that there are the main diffraction peaks corresponding to the basal spacing of 3.90 or $3.25 \mathrm{~nm}$ in the WAXD patterns of BIIR- $T_{0}$ and EPDM- $T_{0}$ (uncured samples), respectively, while the original gallery height of OMC (I.30P) is $2.36 \mathrm{~nm}$, indicating that nanocomposites with an intercalated structure have 
been obtained by melt blending. BIIR is a polar rubber with a $\mathrm{Br}$ content of $1.8 \%$, while EPDM is a non-polar rubber. According to the theory of polymer melt intercalation $[19,20]$, the higher the polarity of the polymer the higher the interaction between the polymer molecules and clay layers, facilitating intercalation of polymer chains into inter space of the silicate.

In the wide-angle X-ray diffraction (WAXD) analysis, the gallery height of the clay is calculated by the Bragg equation, Equation (1):

$2 d \sin \theta=n \lambda, n=1,2,3, \ldots$

where $d$ is the interplanar spacing; $2 \theta$ is the diffraction angle or Bragg angle; $n$ is the order of the diffracted beam; and $\lambda$ is the wavelength of the radiation. Because of the lower order degree of OMC, the width of the basal diffraction peak (001) is relatively large and the high order diffraction peaks offset to a certain degree; and as a result the $d$ values of the high order diffraction peaks and basal diffraction peak are just approximate multiples. For example, aside from the basal diffraction peak located at $3.90 \mathrm{~nm}$, the reflection peaks at 1.93 and $1.28 \mathrm{~nm}$ with descending intensity were observed in the WAXD pattern of uncured BIIRCN, and these two reflection peaks have the relationship of approximate multiples with the main diffraction peak.

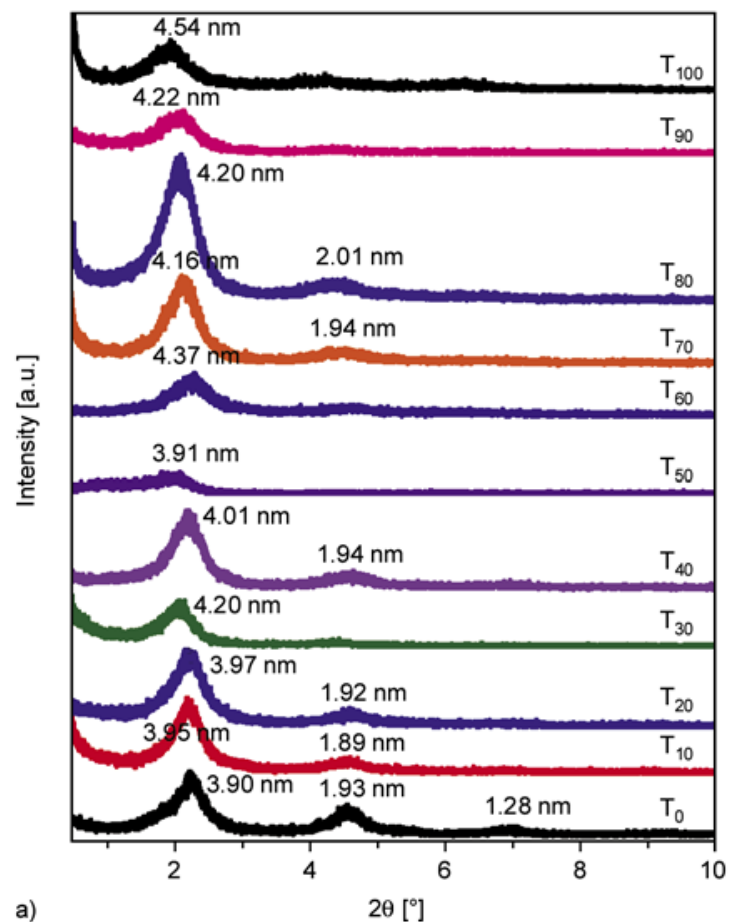

Therefore, we attribute these two diffraction peaks (i.e., (002) and (003)) to the high order diffraction peak of basal one (001). Similarly, other EPDMCN samples at different curing stages $\left(T_{10}, T_{20}\right.$, etc.) also show such high order diffraction peaks. These results indicate that the intercalated structure of clay in the rubber matrix have relative high order degree. As the curing reaction proceeds, the basal diffraction (001) peaks for both of BIIRCN and EPDMCN undergo an obvious change. The interlayer spaces $\left(D_{001}\right)$ corresponding to main diffraction peaks for cured BIIRCN and EPDMCN were significantly higher than those for uncured nanocomposites (i.e., $T_{0}$ samples), indicating further intercalation of rubber molecules during the curing process.

In previous reports [16], it was speculated that the microstructure of RCN could change only during the initial period of the curing course, when the viscosity of the system is still relatively low. However, our results show that even beyond the curing stage of $T_{90}$, the intercalated structure of clay still changes apparently with increasing curing time. At the curing time of $T_{90}$, the vast majority of rubber chains have formed a three-dimensional network structure by chemical crosslinking, but the crosslinking density is not high, generally in the range of $10^{-4}$ to $10^{-5} \mathrm{~mol} / \mathrm{cm}^{3}$. There are the segments of rubber

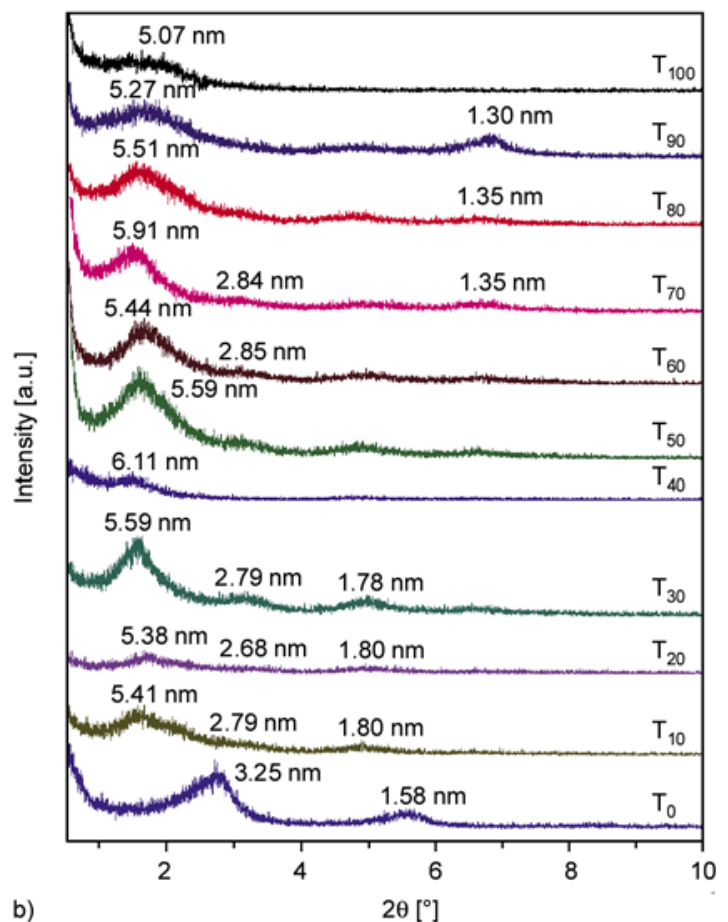

Figure 2. WAXD patterns of (a) BIIRCN and (b) EPDMCN at different curing stages. All curves were shifted vertically for clarity. 
chains having dozens of or even hundreds of repeating units between cross-linking sites, which still maintain a high mobility. The high temperature of the curing process further enhances the activity of the molecular segments. Consequently, significant changes in the intercalated structure of are still possible at the later stages of the curing course.

Aside from the (001) reflection peak, the higher order reflection peaks can be observed in the WAXD patterns of some BIIRCNs and EPDMCNs at different curing stages. The appearance of these high order diffraction peaks indicates that the intercalated structure of the clay could maintain relatively high order degree, though the interlayer space undergone large changes during the vulcanization course. In the WAXD patterns of some EPDMCNs at later curing stages of $T_{70}, T_{80}$ and $T_{90}$, except for the main diffraction peak at low angles, the small diffraction peaks at high angles, corresponding to $\sim 1.30 \mathrm{~nm}$ were observed. They are not the higher order reflection peaks of the main diffraction peak because of the large deviations from integral multiples of the main diffraction peak. The interlayer space of $\sim 1.30 \mathrm{~nm}$ is significantly smaller than the initial interlayer space $(2.36 \mathrm{~nm})$ of OMC (I.30P), but is close to that for inorganic clay. These results show that collapse of the intercalated structure also occurred during the curing process of EPDMCN [21], even formed some inorganic clay.

To further study the changes in intercalated structure during the curing reaction, we plotted the variation of the relative $D_{001}$ values (normalized to the $D_{001}$ values for the uncured samples at $T_{0}$ ) of OMC with the curing stage, as shown in Figure 3. For both BIIRCN and EPDMCN, the interlayer space of OMC changes significantly in the initial few seconds of the curing reaction, i.e., it increases first, reaches a maximum at a certain curing time, and then decreases. The basal interlayer spacing $\left(D_{001}\right)$ gradually increases in BIIRCN, but decreases in EPDMCN during the latter period of the curing course. Previous studies showed that the vulcanization reaction can make rubber molecules intercalate into the silicate gallery, increasing the interlayer space [22], but the vulcanization reaction can also facilitate the de-intercalation of intercalants, resulting in collapse of the intercalated structure-the reduction of interlayer space [21]. High pressure during the curing process would 'squeeze out' the rubber molecules that had been intercalated

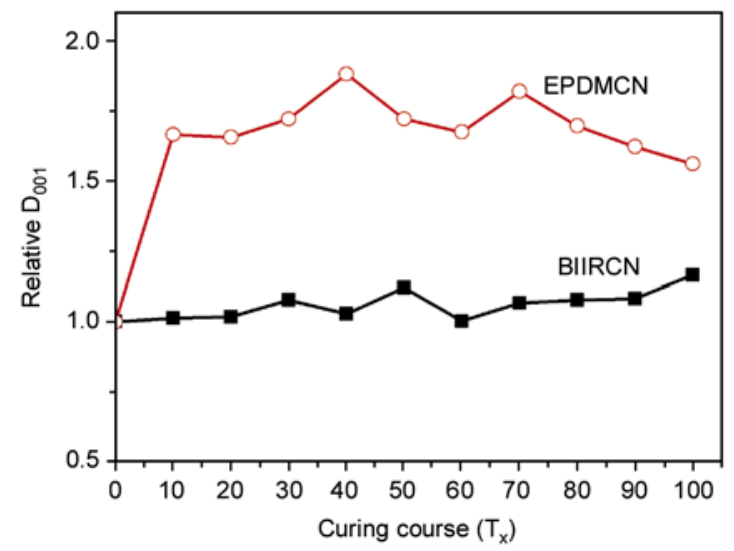

Figure 3. The evolution of relative basal spacing $\left(D_{001}\right)$ of intercalated silicate structure with curing course. The relative $D_{001}$ is the ratio of $D_{001}$ for the sample at $T_{\mathrm{x}}$ curing stage to that at $T_{0}$ curing stage, and $D_{001}$ for $T_{0}$ sample was set as one.

into the clay layers [23], thus reducing the interlayer space. We believe that all these effects are present and compete with each other during the curing process, leading to the complex phenomenon of changes in intercalated structure with increasing curing time. Further studies are still needed to establish the specific mechanisms involved. Another noteworthy phenomenon is that the basal interlayer space $\left(D_{001}\right)$ of the intercalated structure is $4.54 \mathrm{~nm}$ after vulcanization in the polar BIIR, significantly less than the corresponding value of $5.23 \mathrm{~nm}$ in the nonpolar EPDM.

We can draw the conclusion that the change in $D_{001}$ value is much larger in the non-polar EPDM system than in the polar BIIR system. In the polar BIIR system, the change in $D_{001}$ value is less than $10 \%$, while the increase in $D_{001}$ value is over $80 \%$ in the non-polar EPDM system.

\subsection{Effects of OMC on the curing process}

The influence of OMC on vulcanization reactions was believed to be an important factor affecting the microstructural change of RCNs during vulcanization. Most previous studies about the vulcanization kinetic of RCNs indicted that addition of OMC would considerably increase curing rate and crosslinking density of various rubber compounds, including NR [24, 25], ENR [26], BR [27, 28], SBR [29], EAR [30], NBR [31], and NBR/SBR blend [32]. On the other hand, some studies [12,33] on EPDM/OMC systems shown that addition of OMC prolonged the optimum curing time and reduced the 
cross-linking density of the composites. As shown by above experimental results, the intercalated structure of clay in the EPDMCN had changed much more intensively than that in the BIIRCN during the curing process. In this work, therefore, the EPDM system was selected as an example to discuss the effect of OMC on curing process.

The vulcanization curves presented in Figure 4 and the corresponding curing parameters given in Table 3 show the effect of the intercalant (i.e., ODA), pristine clay (i.e., Na-MMT) and OMC on the curing reaction of EPDM. Compared with the neat EPDM compound, addition of Na-MMT shortened the scorch time $\left(T_{10}\right)$, but obviously reduced the CRI, indicating that Na-MMT could suppress curing reactions. On the other hand, the addition of ODA not only shortened the scorch time of EPDM by more than $60 \%$, but also increased the curing rate by about $12 \%$, suggesting that ODA could accelerate curing reactions. The OMC is comprised of Na-MMT and ODA, so that the effects of OMC on vulcanization kinetic should be the combination of the effects of ODA. As shown in Table 3, EPDMCN exhibits reduced $T_{10}$ compared to net EPDM, and the middle value of CRI between those for E-ODA and E-MMT compounds. In addition, the CRI of EPDMCN is closer to that for E-MMT, and smaller than that of net EPDM.

The inner part of the OMC interlayer is enriched with ODA molecules, which can promote the curing reaction. Therefore, the crosslinking rate of the rubber intercalated into the silicate gallery is expected to be obviously higher than that of the rubber outside the layers. For chemical equilibrium, a large number of rubber molecular chains outside

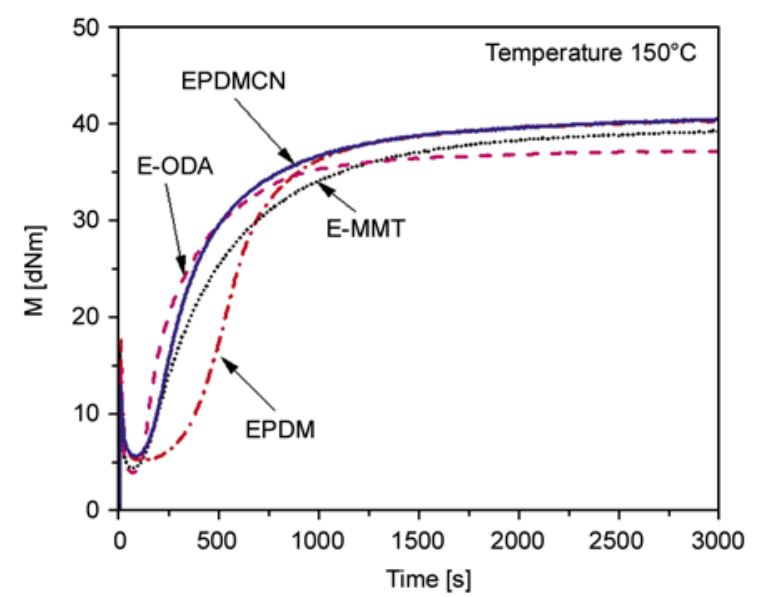

Figure 4. Curing curves of different EPDM compounds with sulfur vulcanization system under $150^{\circ} \mathrm{C}$
Table 3. Curing parameters of different EPDM compounds with sulfur vulcanization system

\begin{tabular}{|l|c|c|c|c|c|c|}
\hline \multirow{3}{*}{ Samples } & \multicolumn{7}{|c|}{ Curing parameter } \\
\cline { 2 - 7 } & $\begin{array}{c}\mathbf{T}_{\mathbf{1 0}} \\
{[\mathbf{m i n}]}\end{array}$ & $\begin{array}{c}\mathbf{T}_{\mathbf{9 0}} \\
{[\mathbf{m i n}]}\end{array}$ & $\begin{array}{c}\mathbf{C R I}^{\mathbf{a}} \\
{\left[\mathbf{m i n}^{\mathbf{- 1}} \mathbf{]}\right.}\end{array}$ & $\begin{array}{c}\mathbf{M}_{\mathbf{m a x}} \\
{[\mathbf{d N m}]}\end{array}$ & $\begin{array}{c}\mathbf{M}_{\mathbf{m i n}} \\
{[\mathbf{d N m}]}\end{array}$ & $\begin{array}{c}\mathbf{\Delta M}^{\mathbf{b}} \\
{[\mathbf{d N m}]}\end{array}$ \\
\hline EPDM & 5.73 & 17.83 & 8.26 & 40.35 & 5.21 & 35.14 \\
\hline E-MMT & 2.68 & 20.88 & 5.49 & 39.45 & 4.38 & 35.07 \\
\hline E-ODA & 2.15 & 12.98 & 9.23 & 37.54 & 3.91 & 33.53 \\
\hline EPDMCN & 2.93 & 20.07 & 5.83 & 41.26 & 5.64 & 35.62 \\
\hline
\end{tabular}

${ }^{\mathrm{a}} \mathrm{CRI}$ is abbreviation of curing rate index, defined as $100 /\left(T_{90}-T_{10}\right)$.

${ }^{\mathrm{b}} \Delta M$ is the difference between $M_{\max }$ and $M_{\min }$.

the layers would be driven to further intercalate into the silicate gallery, participating in the crosslinking reaction in the interlayer of $\mathrm{OMC}$ and expanding the interlayer spacing of the OMC. It has been reported [21] that ODA can react with curing agents to form intermediate compounds. These compounds may migrate into the rubber matrix to take part in the vulcanization process, thus the intercalants would be extracted from the clay galleries, with a resultant confinement and even deintercalation. For the EPDMCN at later period of vulcanization course in this study, the similar phenomenon has also been observed (see Figure 2).

As shown in Figure 1, EPDMCN has higher curing rate (i.e., smaller value of $T_{90}-T_{10}$ ) and higher crosslinking density (i.e., higher value of $M_{\max }-M_{\min }$ ) than BIIRCN, though they have the same compound recipes (see Table 1), likely due to relatively high unsaturated degree of EPDM. Therefore, the cross-linking reactions in EPDMCN should be more intense than those in BIIRCN. Thus the driving force for further intercalation of rubber molecules into silicate gallery or the collapse of intercalated structure caused by de-adsorption of intercalant would be greater in EPDMCN. As a result, the interlayer spacing of intercalated silicate in EPDMCN changed with vulcanization course larger and more violently, also resulting in some collapsed structures. In our previous studies on IIRCNs [17], we also found that when curing reaction is more severe by raising the curing temperature, more collapses structure would be generated in the cured nanocomposites.

\subsection{The evolution of spatial dispersion of organically modified clay during the curing process}

Transmission electron microscopy (TEM) is an effective means to observe the morphology and 
spatial dispersion of nano-clay in rubber matrix. TEM images of BIIRCNs and EPDMCNs at the representative curing times of $T_{0}, T_{10}, T_{50}$, and $T_{100}$ were displayed in Figure 5 and 6 to reflect the changes in spatial dispersion of clay in the matrix during the entire curing process. In these figures, the lighter phase and the darker lines or phase represent the rubber matrix and $\mathrm{OMC}$, respectively.

Figure 5 shows that the dispersion of clay is uniform in BIIR- $T_{0}$ (uncured BIIRCN). BIIR- $T_{0}$ contains the least amount of clay aggregates, and the size of the aggregates was the smallest (about $20 \mathrm{~nm}$ in thickness and $500 \mathrm{~nm}$ in length). The amount of clay aggregates increases significantly in BIIR- $T_{10}$. The dispersion state of the clay deteriorates with increasing curing time. The amount and size of clay aggregates continue to increase in BIIR- $T_{50}$ and BIIR- $T_{100}$, with local appearances of micron-level aggregates.

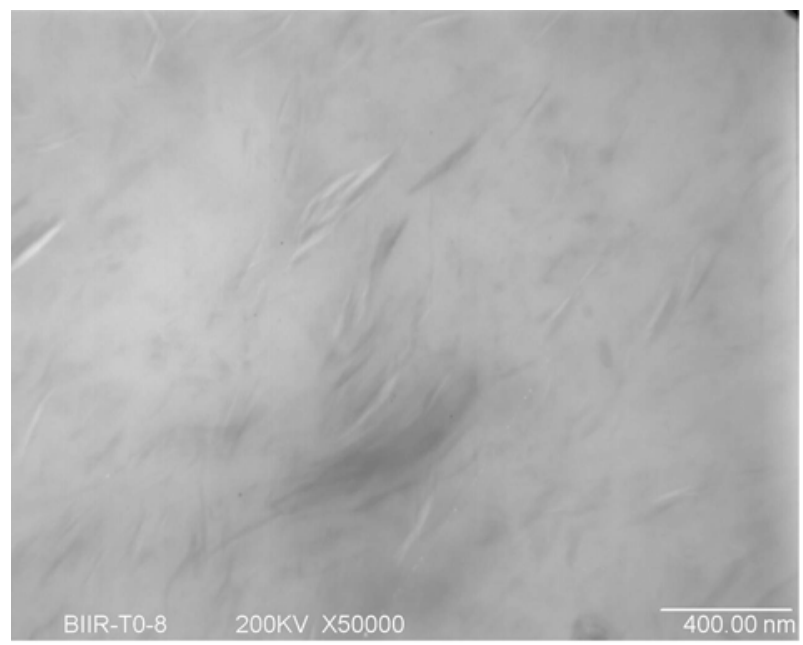

a)

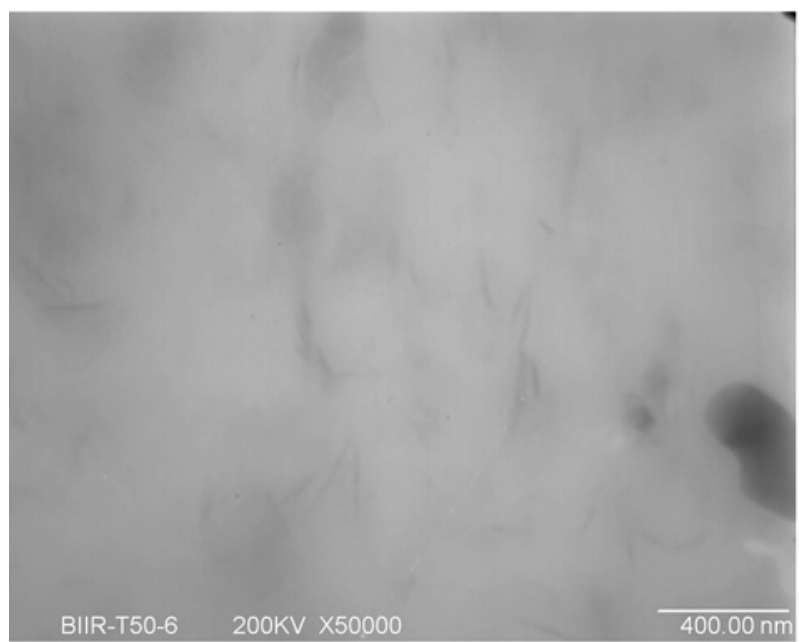
c)
In the curing process of EPDMCN, the evolution of clay dispersion is slightly different from that of BIIRCN. As shown in Figure 6, the clay exists in the form of granules, and large aggregates appear in EPDM- $T_{0}$ (uncured EPDMCN). The dispersion state of clay improved markedly in EPDM- $T_{10}$. The clay exists largely as fine filaments $10 \mathrm{~nm}$ in thickness and $160 \mathrm{~nm}$ in length. After $T_{10}$, the dispersion state deteriorates gradually. Flocculating aggregates are formed by a large number of crystal lamellas in EPDM- $T_{50}$, and the dispersion becomes non-uniform. In EPDM- $T_{100}$, the dispersion degree of clay continues to decrease, with the appearance of large flocculating clay aggregates.

Our previous study on IIRCN [16] revealed that the effect of high pressure on microstructure exhibit time dependence-subjecting to high pressure for short time would not cause obvious change in the microstructure of the nanocomposite. The result

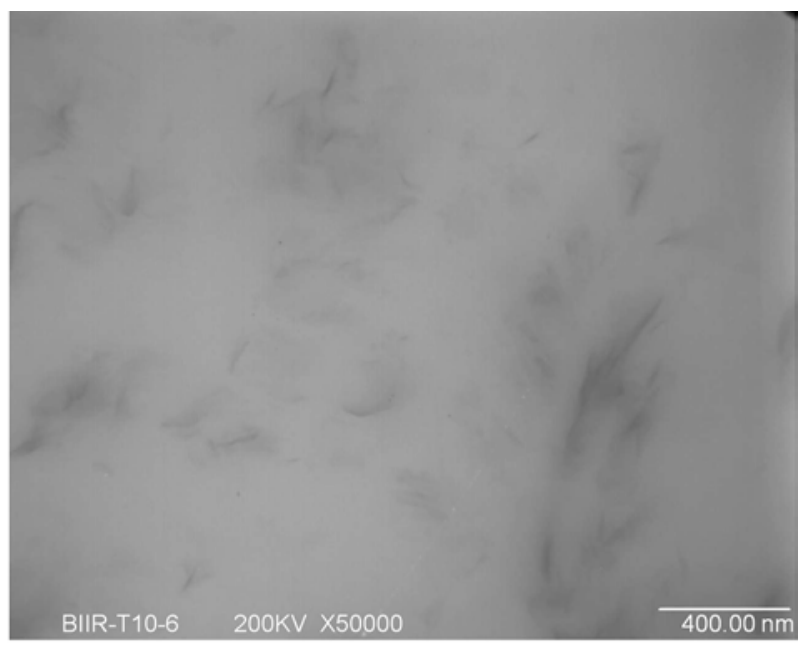

b)

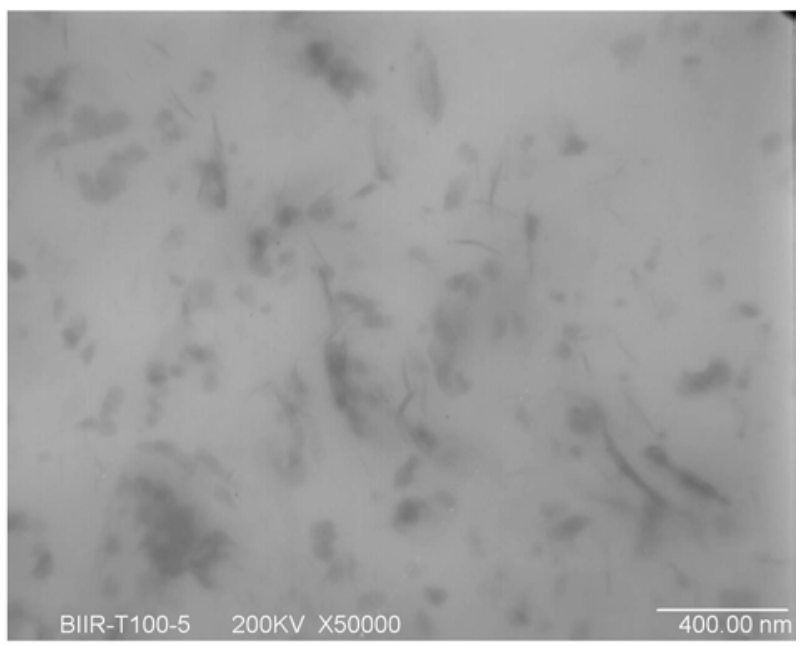

d)

Figure 5. TEM images of BIIRCN at various curing stages ( $\times 50000)$ : (a) $T_{0}$, (b) $T_{10}$, (c) $T_{50}$ and (d) $T_{100}$ 


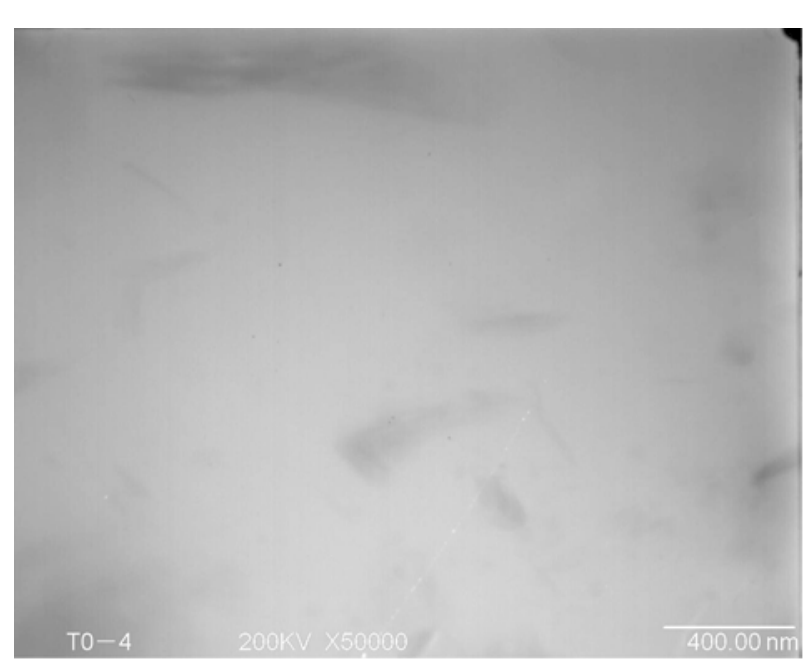

a)

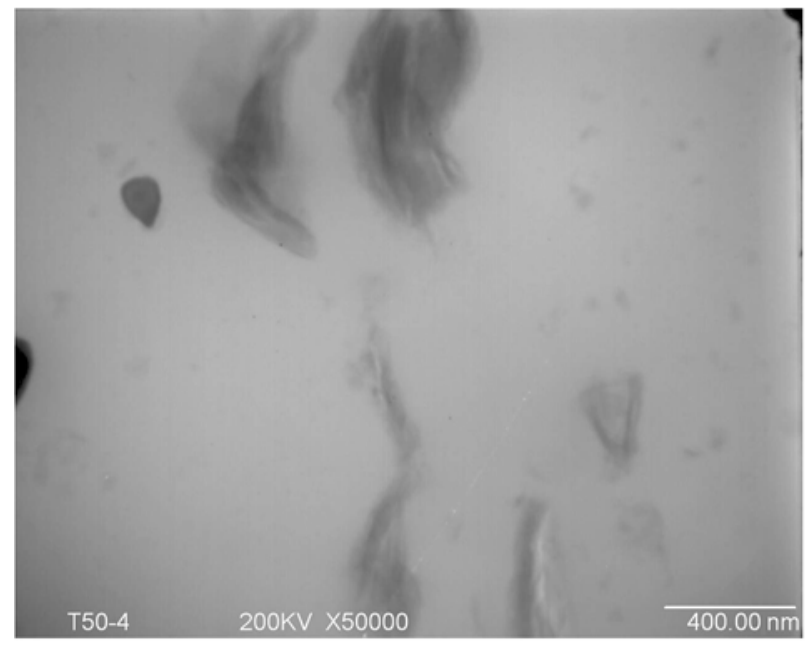

c)

Figure 6. TEM images of EPDMCN at various curing stages (×50 000): (a) $T_{0}$, (b) $T_{10}$, (c) $T_{50}$ and (d) $T_{100}$

shown in Figure 6 suggests that such time dependence for high pressure effect also exists in EPDMCN. As a result, in the initial stage of vulcanization (i.e., before $T_{10}$ ), curing reaction plays a major role on dispersion state of clay, which can drive rubber molecules further intercalate into the silicate gallery and improve the spatial dispersion of clay. On the other hand, with the time for subjecting to high pressure increasing (i.e., in the later stage of vulcanization), the effect of high pressure becomes more and more considerable, generating large flocculates of intercalated silicate, though the interlayer spacing of which is larger than that in uncured nanocomposite.

In comparison of TEM morphology between BIIRCN and EPDMCN (Figure 5 and 6), the spatial dispersion of OMC in EPDMCN is clearly inferior to that in BIIRCN. WAXD results (Figure 2) show the interlayer space of the intercalated structure in persion.

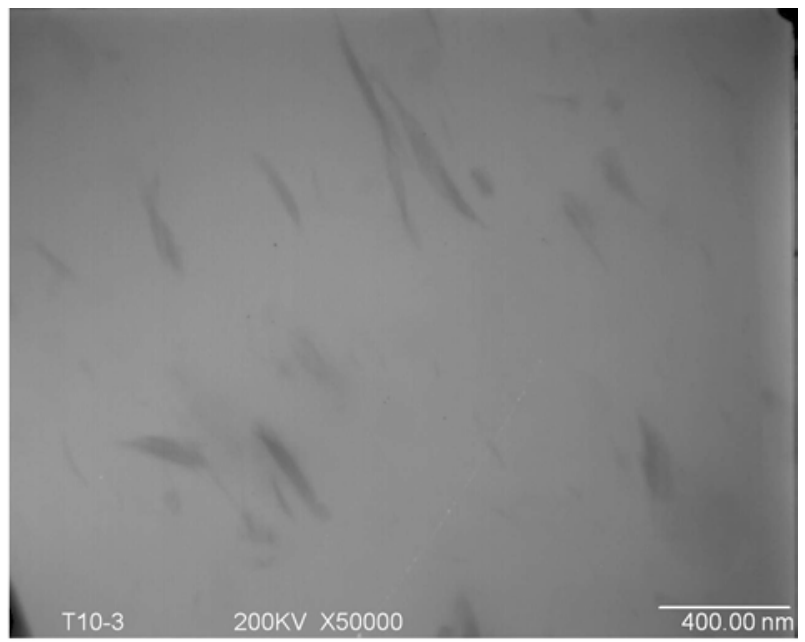

b)

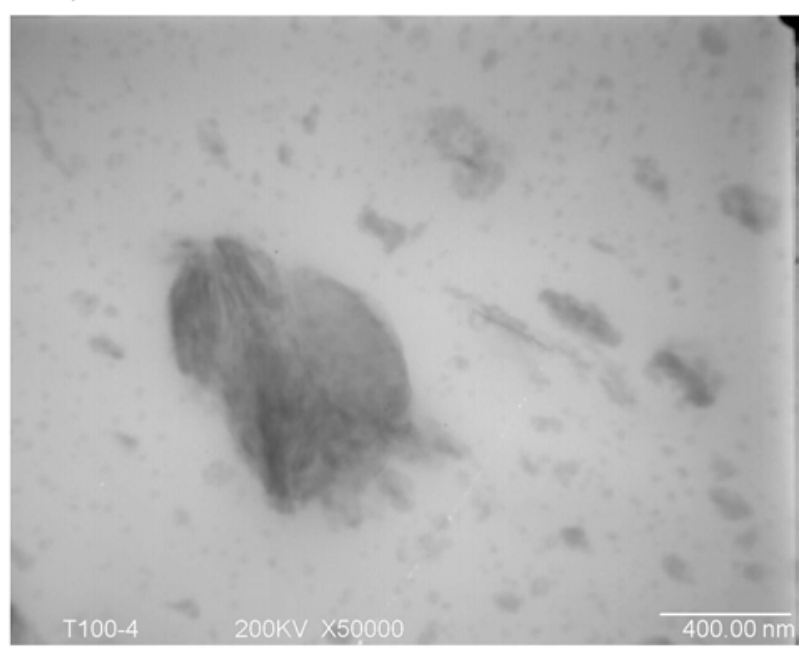

d)

cured EPDMCN is obviously larger than that in cured BIIRCN. These results suggested that the intercalated clay with the larger interlayer space does not necessarily result in the better spatial dis-

\subsection{Impact of the polarity of rubber on the microstructure of rubber/clay nanocomposite}

The above results demonstrate that the RCNs with different polarity show different change trends in both the intercalated structure and spatial dispersion of clay during the vulcanization process. The interlayer space of BIIR- $T_{0}$ is larger than that of EPDM$T_{0}$, while the interlayer space of cured EPDMCN is larger than that of cured BIIRCN and more variable during the curing process. The spatial dispersion of the OMC is obviously better in the polar BIIR than in the non-polar EPDM. The spatial dispersion dete- 
riorates continuously with curing time in BIIRCN, while it improves from $T_{0}$ to $T_{10}$ before worsening with further increasing in curing time in EPDMCN. The vulcanization curves of BIIRCN and EPDMCN given in Figure 1 reveal that the torque difference (i.e., $M_{\max }-M_{\min }$ ) of EPDMCN is significantly higher than that of BIIRCN, and the optimum curing time (i.e., $T_{90}$ ) of the EPDMCN is significantly shorter than that of the BIIRCN, indicating that both the crosslink density of the cured EPDM and its curing rate are much larger than those for the BIIRCN. If only the factor of the mobility of dispersed clay layers in RCNs during vulcanization process were considered, the microstructural changes for EPDMCN would be smaller than those BIIRCN. However, the experimental results show that the opposite fact is true, suggesting that the polarity of matrix rubber might be a more significant factor on the microstructural change than other factors.

Using the polarity of rubber as the starting point, we present a preliminary explanation of the phenomena disclosed in this study on base of the kinetics and thermodynamics of the intercalation of polymer chain into layered silicate. According to the theory on melt polymer intercalation $[19,20]$, the polymer molecules with high polarity have strong interaction with the clay, and this strong interaction can offset some of the entropy decrease caused by confinement of intercalated polymer chains. From the point of view of thermodynamics, the intercalation of polymer with high polarity easily results in the intercalated structure with a larger gallery height. The intercalation of polymer molecules into the silicate gallery is a continuous process of destruction and reconstruction of the interaction between the molecules and the clay. The polar rubber macromolecules have stronger interaction with OMC than non-polar macromolecules, and this stronger interaction is more difficult to be destroyed. From the point of view of kinetics, therefore, the energy barrier against intercalation for polar rubber is higher than that for nonpolar rubber. In the process of mechanical blending rubber with $\mathrm{OMC}$, the strong external shear force can destroy the energy barrier for intercalation, thus facilitating the intercalation process. At this time, the thermodynamic factor should play dominant role in determining the intercalation structure. As a result, the intercalated structure in BIIRCN mixing compound exhibits larger interlayer spacing than that in EPDMCN mixing compound. Accordingly, the spatial dispersion state of OMC in BIIRCN mixing compound is much better than that in EPDMCN. On the contrary, different from the process of mechanical mixing, there is a lack of external strong shear force during the vulcanization process to overcome the energy barrier against intercalation, so kinetics factors play a greater role in further intercalation. EPDM rubber molecules have lower intermolecular forces with clay than BIIR molecules, so the energy barrier for the destruction of the original structure to form the new intercalated structure is smaller for EPDM system than in BIIR system, resulting in a larger interlayer spacing of the intercalated structure in cured EPDMCN than in cured BIIRCN. Accordingly, the change in spatial dispersion state of OMC during vulcanization process in EPDMCN is more intensively than that in BIIRCN.

\section{Conclusions}

(a) The intercalated structure of clay continuously changed throughout the curing process, and such micro-structural changes could occur even after the curing time had reached $T_{90}$. The intercalants ODA of organoclay could shorten the scorch time, and increase the curing rate, so the impact of intercalants on vulcanization kinetic was considered to be primary cause for the evolution of intercalated structure.

(b) Of the two uncured RCNs, uncured BIIRCN has a larger interlayer spacing of the intercalated structure than uncured EPDMC. However, the opposite is true in the cured RCNs. The change in intercalated structure during vulcanization is larger in EPDMCN than in BIIRCN. The spatial dispersion of clay in BIIR, a polar rubber, is superior to that in EPDM, a non-polar rubber. During the vulcanization process, the spatial dispersion state of clay in BIIRCN gradually deteriorates. In the case of EPDMCN, the spatial dispersion of clay increased from $T_{0}$ to $T_{10}$, followed by gradual deterioration with curing time.

(c) For BIIRCN and EPDMCN, sulfur-curing reactions can cause further intercalation and increase the interlayer space, but also possibly result in collapse of intercalated structure. High pressure has negative effects on the dispersion of clay. These factors coexist and compete with each other during 
vulcanization course, leading to complex microstructural evolution behavior. The difference in microstructural evolution during vulcanization between BIIRCN and EPDMCN is interpreted from the viewpoints of thermodynamics and kinetics, and the polarity of the rubber matrix is expected to play a major role.

(d) This work shows that the dispersion state of rubber/clay nanocomposites obtained by the current conventional vulcanization process is not the best. For instance, the dispersion state of clay in EPDMCN is the best at a certain intermediate stage of the curing process, showing the potential for improving the clay dispersion through the optimization of curing parameters. Our previous work [23] has demonstrated that the curing under low pressure can obtain RCN with better dispersion. However, high pressure is necessary for many rubber products in order to adequately fill the mould with complex shape, improve product compactness, and reduce defects. We suggested that performing vulcanization of RCNs under altered pressure, that is using high pressure at the beginning stage but reducing pressure at latter stage, may obtain the RCN with good dispersion, the work on which is still ongoing.

\section{Acknowledgements}

This work was financially supported by New Star Program of Beijing Science and Technology (2006A15), National Outstanding Youth Science Fund (contract grant number: 50725310) and Program for Changjiang Scholars and Innovative Research Team in University (PCSIRT, IRT0807).

\section{References}

[1] Zhang Z., Zhang L., Li Y., Xu H.: New fabricate of styrene-butadiene rubber/montmorillonite nanocomposites by anionic polymerization. Polymer, 46, 129136 (2005).

DOI: $10.1016 /$ j.polymer.2004.11.008

[2] Pramanik M., Srivastava S. K., Samantaray B. K., Bhowmick A. K.: Rubber-clay nanocomposite by solution blending. Journal of Applied Polymer Science, 87, 2216-2220 (2003).

DOI: $10.1002 / a p p .11475$

[3] Hasegawa N., Okamoto H., Kawasumi M., Kato M., Tsukigase A., Usuki A.: Polyolefin-clay hybrids based on modified polyolefins and organophilic clay. Macromolecular Materials and Engineering, 280/281, 76-79 (2000).

DOI: $10.1002 / 1439-2054(20000801) 280: 1<76$ ::aidmame76>3.0.co;2-\#
[4] Varghese S., Karger-Kocsis J., Gatos K. G.: Melt compounded epoxidized natural rubber/layered silicate nanocomposites: Structure-properties relationships. Polymer, 44, 3977-3983 (2003).

DOI: $10.1016 / \mathrm{S} 0032-3861(03) 00358-6$

[5] Ramorino G., Bignotti F., Pandini S., Riccò T.: Mechanical reinforcement in natural rubber/organoclay nanocomposites. Composites Science and Technology, 69, 1206-1211 (2009).

DOI: $10.1016 /$ j.compscitech.2009.02.023

[6] Varghese S., Karger-Kocsis J.: Natural rubber-based nanocomposites by latex compounding with layered silicates. Polymer, 44, 4921-4927 (2003).

DOI: 10.1016/S0032-3861(03)00480-4

[7] Wu Y-P., Jia Q-X., Yu D-S., Zhang L-Q.: Structure and properties of nitrile rubber (NBR)-clay nanocomposites by co-coagulating NBR latex and clay aqueous suspension. Journal of Applied Polymer Science, 89, 3855-3858 (2003).

DOI: $10.1002 / a p p .12568$

[8] Wu Y-P., Zhang L-Q., Wang Y-Q., Liang Y., Yu D-S.: Structure of carboxylated acrylonitrile-butadiene rubber (CNBR)-clay nanocomposites by co-coagulating rubber latex and clay aqueous suspension. Journal of Applied Polymer Science, 82, 2842-2848 (2001). DOI: $10.1002 /$ app. 2138

[9] Varghese S., Karger-Kocsis J.: Melt-compounded natural rubber nanocomposites with pristine and organophilic layered silicates of natural and synthetic origin. Journal of Applied Polymer Science, 91, 813819 (2004).

DOI: $10.1002 /$ app. 13173

[10] Kim J-T., Oh T-S., Lee D-H.: Morphology and rheological properties of nanocomposites based on nitrile rubber and organophilic layered silicates. Polymer International, 52, 1203-1208 (2003).

DOI: $10.1002 /$ pi. 1249

[11] Kim J-T., Oh T-S., Lee D-H.: Preparation and characteristics of nitrile rubber (NBR) nanocomposites based on organophilic layered clay. Polymer International, 52, 1058-1063 (2003). DOI: $10.1002 /$ pi.1110

[12] Zheng H., Zhang Y., Peng Z., Zhang Y.: Influence of clay modification on the structure and mechanical properties of EPDM/montmorillonite nanocomposites. Polymer Testing, 23, 217-223 (2004).

DOI: 10.1016/S0142-9418(03)00097-7

[13] Schön F., Thomann R., Gronski W.: Shear controlled morphology of rubber/organoclay nanocomposites and dynamic mechanical analysis. Macromolecular Symposia, 189, 105-110 (2002). DOI: $10.1002 /$ masy.200290000

[14] Gatos K. G., Thomann R., Karger-Kocsis J.: Characteristics of ethylene propylene diene monomer rubber/ organoclay nanocomposites resulting from different processing conditions and formulations. Polymer International, 53, 1191-1197 (2004).

DOI: $10.1002 /$ pi.1556 
[15] Sadhu S., Bhowmick A. K.: Preparation and properties of nanocomposites based on acrylonitrile-butadiene rubber, styrene-butadiene rubber, and polybutadiene rubber. Journal of Polymer Science Part B: Polymer Physics, 42, 1573-1585 (2004).

DOI: $10.1002 /$ polb. 20036

[16] Liang Y-R., Ma J., Lu Y-L., Wu Y-P., Zhang L-Q., Mai Y-W.: Effects of heat and pressure on intercalation structures of isobutylene-isoprene rubber/clay nanocomposites. I. Prepared by melt blending. Journal of Polymer Science Part B: Polymer Physics, 43, 2653-2664 (2005).

DOI: $10.1002 /$ polb.20555

[17] Lu Y-L., Li Z., Mao L-X., Li Y., Wu Y-P., Liang Y-R., Zhang L-Q.: Impact of curing temperature on microstructures and properties of isobutylene-isoprene rubber/clay nanocomposites. Journal of Applied Polymer Science, 110, 1034-1042 (2008).

DOI: $10.1002 /$ app.28690

[18] Lu Y-L., Liang Y-R., Wu Y-P., Zhang L-Q.: Effects of heat and pressure on microstructures of isobutyleneisoprene rubber (IIR)/clay nanocomposites. Macromolecular Materials and Engineering, 291, 27-36 (2006).

DOI: $10.1002 /$ mame.200500319

[19] Vaia R. A., Giannelis E. P.: Polymer melt intercalation in organically-modified layered silicates: Model predictions and experiment. Macromolecules, 30, 8000 8009 (1997).

DOI: $10.1021 / \mathrm{ma9} 603488$

[20] Vaia R. A., Jandt K. D., Kramer E. J., Giannelis E. P.: Kinetics of polymer melt intercalation. Macromolecules, 28, 8080-8085 (1995).

DOI: $10.1021 / \mathrm{ma} 00128 \mathrm{a} 016$

[21] Gatos K. G., Karger-Kocsis J.: Effects of primary and quaternary amine intercalants on the organoclay dispersion in a sulfur-cured EPDM rubber. Polymer, 46, 3069-3076 (2005).

DOI: $10.1016 /$ j.polymer.2005.01.095

[22] Usuki A., Tukigase A., Kato M.: Preparation and properties of EPDM-clay hybrids. Polymer, 43, 21852189 (2002).

DOI: 10.1016/S0032-3861(02)00013-7

[23] Liang Y-R., Lu Y-L., Wu Y-P., Ma Y., Zhang L-Q.: Pressure, the critical factor governing final microstructures of cured rubber/clay nanocomposites. Macromolecular Rapid Communications, 26, 926-931 (2005). DOI: $10.1002 /$ marc. 200500077

[24] Arroyo M., López-Manchado M. A., Herrero B.: Organo-montmorillonite as substitute of carbon black in natural rubber compounds. Polymer, 44, 2447-2453 (2003).

DOI: 10.1016/S0032-3861(03)00090-9
[25] López-Manchado M. A., Arroyo M., Herrero B., Biagiotti J.: Vulcanization kinetics of natural rubberorganoclay nanocomposites. Journal of Applied Polymer Science, 89, 1-15 (2003).

DOI: 10.1002 app.12082

[26] Teh P. L., Mohd Ishak Z. A., Hashim A. S., KargerKocsis J., Ishiaku U. S.: Effects of epoxidized natural rubber as a compatibilizer in melt compounded natural rubber-organoclay nanocomposites. European Polymer Journal, 40, 2513-2521 (2004).

DOI: 10.1016/j.eurpolymj.2004.06.025

[27] Kim M-S., Kim D-W., Chowdhury S. R., Kim G-H.: Melt-compounded butadiene rubber nanocomposites with improved mechanical properties and abrasion resistance. Journal of Applied Polymer Science, 102, 2062-2066 (2006).

DOI: 10.1002/app.23738

[28] Kim M-S., Kim G-H., Chowdhury S. R.: Polybutadiene rubber/organoclay nanocomposites: Effect of organoclay with various modifier concentrations on the vulcanization behavior and mechanical properties. Polymer Engineering and Science, 47, 308-313 (2007).

DOI: 10.1002/pen.20709

[29] Mousa A., Karger-Kocsis J.: Rheological and thermodynamical behavior of styrene/butadiene rubberorganoclay nanocomposites. Macromolecular Materials and Engineering, 286, 260-266 (2001).

DOI: 10.1002/1439-2054(20010401)286:4<260::AIDMAME260>3.0.CO;2-X

[30] Mathew G., Rhee J. M., Lee Y-S., Park D. H., Nah C.: Cure kinetics of ethylene acrylate rubber/clay nanocomposites. Journal of Industrial and Engineering Chemistry, 14, 60-65 (2008).

DOI: $10.1016 /$ j.jiec.2007.07.001

[31] Choi D., Kader M. A., Cho B-H., Huh Y-I., Nah C.: Vulcanization kinetics of nitrile rubber/layered clay nanocomposites. Journal of Applied Polymer Science, 98, 1688-1696 (2005).

DOI: $10.1002 / a p p .22341$

[32] Essawy H., El-Nashar D.: The use of montmorillonite as a reinforcing and compatibilizing filler for NBR/ SBR rubber blend. Polymer Testing, 23, 803-807 (2004).

DOI: $10.1016 /$ j.polymertesting.2004.03.003

[33] Ma Y., Wu Y-P., Wang Y-Q., Zhang L-Q.: Structure and properties of organoclay/EPDM nanocomposites: Influence of ethylene contents. Journal of Applied Polymer Science, 99, 914-919 (2006).

DOI: 10.1002/app.22247 